\title{
Role of Granulosa Cells in the Aging Ovarian Landscape: A Focus on Mitochondrial and Metabolic Function
}

\author{
Hannah C. Alberico and Dori C. Woods* \\ Department of Biology, Northeastern University, Boston, MA, United States
}

Mitochondria are at the intersection of aging and fertility, with research efforts centered largely on the role that these specialized organelles play in the relatively rapid decline in oocyte quality that occurs as females approach reproductive senescence. In addition to various roles in oocyte maturation, fertilization, and embryogenesis, mitochondria are critical to granulosa cell function. Herein, we provide a review of the literature pertaining to the role of mitochondria in granulosa cell function, with emphasis on how mitochondrial aging in granulosa cells may impact reproduction in female mammals.

OPEN ACCESS

Edited by:

Huai L. Feng,

NewYork-Presbyterian, Weill Cornell Medical Center, United States

Reviewed by: Ray Rodgers, University of Adelaide, Australia Richard Ivell, University of Nottingham, United Kingdom

*Correspondence: Dori C. Woods

d.woods@northeastern.edu

Specialty section:

This article was submitted to Reproduction, a section of the journal

Frontiers in Physiology

Received: 23 October 2021 Accepted: 29 December 2021 Published: 27 January 2022

Citation:

Alberico $\mathrm{HC}$ and Woods DC (2022) Role of Granulosa Cells in the Aging Ovarian Landscape:

A Focus on Mitochondrial and Metabolic Function.

Front. Physiol. 12:800739. doi: $10.3389 /$ fphys.2021.800739
Keywords: granulosa cells, ovarian aging, mitochondria, reproduction, oocytes

\section{INTRODUCTION}

Mitochondria are bacterial in origin with an ancestral genome descended from Alphaproteobacteria, which incorporated into the cytoplasm following endosymbiosis over 1.45 billion years ago (Gray, 2012). Subsequently, the internalized bacterial genome evolved into the mitochondrial genome, and the ubiquitous organelle is now a critical participant in eukaryotic cellular function. Mitochondria harbor their own genetic material (mtDNA), distinct from the nuclear genome (nDNA), which in mammals is nearly exclusively inherited through the maternal germline, with rare instances of heteroplasmy as a result of paternal inheritance reported (Mitchell, 1961; Huttemann et al., 2008; Perry et al., 2011; Luo et al., 2018; Annis et al., 2019). The circular genome of the mitochondrion is small-in humans only approximately $16 \mathrm{~kb}$-and encodes for 37 genes, including 13 proteins associated with the subunits of the electron transport chain (ETC), as well as 2 ribosomal RNAs (rRNAs) and 22 transfer RNAs (tRNAs). The remaining gene products associated with mitochondria, including those used for ETC function, are nuclear encoded. Thus, $99 \%$ of the mitochondrial proteome emanates from the nucleus, highlighting the degree in which mitochondrial: nuclear communication through antegrade and retrograde signaling work in concert. Notably, while mitochondria are well characterized for their role in cellular bioenergetics, these organelles are highly specialized based on tissue- and cell-type, and perform additional functions based on specific cellular demands. These include critical roles in apoptosis, thermogenesis, heme biosynthesis, detoxification, calcium signaling and ion flux, and steroidogenesis, among others (Baughman et al., 2011; Friedman and Nunnari, 2014; Woods, 2017).

In female mammals, mitochondrial function has been studied in detail in the granulosa and theca cells of the developing follicle, as well as in the oocyte and developing embryo. During follicle development, mitochondria within the oocyte undergo substantial numerical expansion through mitochondrial biogenesis, while mechanisms for mitochondrial autophagy (e.g., mitophagy) are 
latent until the $4-8$ cell stage of embryogenesis (Tsukamoto et al., 2008; Boudoures et al., 2017). At the time of ovulation, mitochondrial biogenesis ceases and does not resume until the blastocyst stage, around the time of implantation. Thus, during each cell division mitochondrial content and mtDNA copy number are reduced on a per-cell basis, and must maintain a critical threshold number (e.g., 40,000-50,000 copies of mtDNA) for successful development to the blastocyst and subsequent implantation (Wai et al., 2010). It has been estimated in oocytes that on a per-mitochondrion basis each organelle harbors 1-2 copies of mtDNA (Piko and Matsumoto, 1976), although this has yet to be empirically determined. Though slightly higher, our analysis of single oocyte mitochondria collected from both young (6-weeks old) and aged (12-months old) female mice by single-molecule PCR (smPCR) is in accordance with this estimation $(2.27 \pm 0.53$ in young samples, $3.27 \pm 1.13$ in aged samples; N.S) (Figure 1). However, we have observed that smPCR of oocyte mtDNA produces negative results more frequently than mitochondria of other cell types (data not shown). Since we do not know the biological significance of this (if any), mitochondrial samples that were determined to have zero mtDNA copies in this experiment have been excluded from analysis, potentially leading to artificial elevation of the values reported in Figure 1.

Importantly, the endocrine function of the ovary is dependent upon the ovarian follicle, which synchronizes with the hypothalamic-pituitary-gonadal (HPG) axis (reviewed in Truman et al., 2017). Localized primarily within the ovarian cortex, ovarian follicles are considered the functional units of the ovary and are comprised of an oocyte surrounded by granulosa cells or, at the resting primordial phase, pre-granulosa cells, and enclosed within an extracellular matrix (ECM)-rich basement membrane. Research in rodent models has demonstrated that the pre-granulosa cells enclosed within primordial follicles are largely non-proliferative, although mitotically active pre-granulosa cells can be observed within primordial follicles of the medulla (Hirshfield and DeSanti, 1995). As follicles mature, granulosa cells transition from a squamous single layer to a cuboidal and multilaminar proliferative phenotype, and a theca layer is recruited. Together, the somatic cells of the follicle respond to circulating gonadotropins (i.e., FSHR and LHR) to generate the sex steroids (i.e., estrogens, progestins, and androgens), which is a mitochondrial-dependent process. At ovulation, the granulosa cells immediately surrounding the oocyte, termed cumulus granulosa cells, remain with the ovulated egg, while the mural granulosa cells along with the theca cells are retained in the ovary and functionally differentiate into the corpus luteum (Smith et al., 1994). Thus, a growing follicle consists of four cell types-an oocyte, mural granulosa cells, cumulus granulosa cells, and the cells comprising the theca interna and theca externa. Although both the theca and granulosa cells participate in endocrine function, granulosa cells specifically work in concert with the oocyte through bi-directional communication working via paracrine factors as well as gap junction signaling, which ultimately results in the growth and maturation of fertilizationcompetent eggs (Eppig et al., 2002; Gittens et al., 2005; Kidder and Vanderhyden, 2010; Wigglesworth et al., 2013).
Coincident with advancing maternal age, the number of follicles within the ovary wanes, and concurrently the quantity and quality of fertilization-competent eggs declines. The decline in oocyte quality is, at least in part, attributed to impaired mitochondrial function (reviewed in Woods et al., 2018). While many endpoints have been used to demarcate egg quality in the context of maternal aging, mitochondrial derangement and abnormal chromosomal segregation are repeatedly and persistently cited as instigators of developmental incompetence and embryonic failure (Henderson and Edwards, 1968; Hook, 1981; Hassold and Chiu, 1985; Battaglia et al., 1996; Tarin et al., 2001; Eichenlaub-Ritter et al., 2004; Hunt and Hassold, 2008; Pan et al., 2008; Selesniemi et al., 2011; Faraci et al., 2018; Woods et al., 2018). Highlighting the impact of mitochondrial function on the reproductive potential of oocytes with age, interventions aimed at modulating pathways associated with mitochondrial homeostasis result in several benefits, including improved spindle assembly, chromosomal segregation, and fertility outcomes (Tarin et al., 2002; Bentov et al., 2011; Selesniemi et al., 2011; Woods and Tilly, 2015; Liu et al., 2018; Bertoldo et al., 2020).

In addition to the well-characterized role of mitochondrial dysfunction with age on oocytes, the mitochondria of granulosa cells also reflect age-associated abnormalities. Complications in mitochondrial processes and function include a decrease in mitochondrial DNA (mtDNA) copy number, modifications in ultrastructure, increase in the frequency of mtDNA deletions and mutations, altered mitochondrial membrane potential $\left(\Delta \psi_{\mathrm{m}}\right)$ and metabolic function, and a reduced capacity for steroid hormone biosynthesis, among others (Tatone et al., 2011; Liu et al., 2017; MacDonald et al., 2017; Sreerangaraja Urs et al., 2020). Accordingly, it has been postulated that granulosa cell mitochondria undergo changes with age that can impart negatively upon oocyte quality and function. Similarly, it has been proposed that granulosa cell metabolites and quantifiable mitochondrial features can serve as molecular biomarkers for oocyte competence (Tatone et al., 2011; Boucret et al., 2015; Ogino et al., 2016; Desquiret-Dumas et al., 2017; Liu et al., 2017; MacDonald et al., 2017; Sreerangaraja Urs et al., 2020). Herein, we review the role of mitochondria in granulosa cells, with a focus on how mitochondrial function and dynamics within granulosa, cumulus, and luteal cells is altered with advancing maternal age.

\section{MITOCHONDRIA AS EFFECTORS OF GRANULOSA CELL FUNCTION}

Of the six classes of steroid hormones, three are synthesized in the ovary (Miller, 2013). In the two-cell model for steroidogenesis progestins and androgens are synthesized in the theca cells, and further converted to estrogens in the adjacent granulosa cells, with granulosa cells also producing progestins (Jamnongit and Hammes, 2006). The process of steroidogenesis is dependent upon steroidogenic cell-specific mitochondria which harbor specialized enzymes required for steroid hormone biosynthesis. The role of granulosa and theca cells, as well as mitochondria, in steroid hormone production has been well studied and summarized elsewhere 
(Jamnongjit and Hammes, 2006; Miller, 2013; Yazawa et al., 2019). Specifically, in granulosa cells, mitochondria are critical for two processes integral to steroid hormone production; cholesterol import into mitochondria, and the enzymatic conversion of cholesterol into steroid hormones. The transfer of cholesterol from the cytoplasm into mitochondria is initialized following gonadotropin stimulation, and is facilitated by Steroid Acute Regulatory Protein (StAR), which interacts with a protein assembly including the $18 \mathrm{KDa}$ translocator protein (TSPO) and the voltage-dependent anion channel (VDAC1) on the outer mitochondrial membrane (OMM) to direct cholesterol to the inner mitochondrial membrane (IMM), where it is converted to pregnenolone and then progesterone, carried out by the mitochondrial enzymes CYP1lal and 3-beta-hydroxysteroid dehydrogenase (HSD3 $\beta 1$ ), respectively (Kiriakidou et al., 1996; Miller, 2013). Not surprisingly, alteration of StAR and HSD3 $\beta 1$ protein levels have been linked to infertility (Feuerstein et al., 2007; Hamel et al., 2008; Wathlet et al., 2012; Sreerangaraja Urs et al., 2020). Furthermore, it is the transport of cholesterol into the IMM that is considered the rate-limiting step in steroidogenesis (Stocco, 2001), with functional mitochondria maintaining $\Delta \psi_{\mathrm{m}}$ critical to this process (Artemenko et al., 2001; Allen et al., 2006; Miller, 2013, 2017; Sreerangaraja Urs et al., 2020).

Intact $\Delta \psi_{\mathrm{m}}$ has been demonstrated to be requisite for steroidogenesis in Leydig cells (Allen et al., 2006), and been further associated with steroidogenic capacity of granulosa cells in bovine models (Ostuni et al., 2018). The pivotal role of mitochondria in modulation of steroidogenesis in granulosa cells has also been linked to fertility outcomes in women. In a recent study evaluating whether mitochondrial function is correlated with IVF outcomes, mitochondrial properties were evaluated in patient cohorts [e.g., endometriosis, ovarian endometrioma, endometriosis without ovarian endometrioma, and polycystic ovary syndrome (PCOS)], as compared to those undergoing IVF for male-factor infertility (Sreerangaraja Urs et al., 2020). Using flow cytometry for the quantitative evaluation of markers for mitochondrial function and quality in cumulus cells, including $\Delta \psi_{\mathrm{m}}$ and mitochondrial mass, the authors determined that mitochondrial dysfunction is associated with a decrease in estradiol (E2), and is further linked to a global decline in fertility, including oocyte maturation and fertilization rates. Specifically, increased $\Delta \psi_{\mathrm{m}}$ in cumulus cells was positively correlated with E2 content, whereas reduced mitochondrial mass was associated with infertility. These findings are consistent with previous work demonstrating marked reductions in $\Delta \psi_{\mathrm{m}}$ in granulosa cells from women with PCOS, and, to a lesser extent, endometriosis (Karuputhula et al., 2013).

The reduction of steroid hormone biosynthesis with age is largely attributed to a decline in the number of ovarian follicles, and thereby a reduction in functional steroid-producing cells. It is no surprise then, that hallmarks associated with reproductive aging and senescence in women are those that are measurable based on a decline in granulosa cell activity, such as a decrease in circulating levels of anti-Müllerian hormone (AMH; produced by immature granulosa cells), reduced levels of estrogen (produced by mature granulosa cells), and elevated circulating levels of FSH (due to a lack of inhibin production by granulosa cells). These well-established clinical determinants of reproductive function have long-solidified the significant role of granulosa cells as indicators of the aging of the female reproductive tract. As a number of mitochondrial deficits are known to occur with age, it is possible that vast changes in mitochondrial properties may lead to age-associated granulosa cell dysfunction, including abnormal steroidogenesis. For example, in female patients undergoing IVF, $\Delta \psi_{\mathrm{m}}$ is significantly reduced in patients $\geq 38$ years of age (Liu et al., 2017), although an earlier study showed no difference with age (Muhammad et al., 2009). This discrepancy could potentially be attributed to the differences in methodology employed with the later study using a combination of quantitative endpoints, such as flow-cytometry and quantitative microscopy, and the earlier study relying on a qualitative assessment based on fluorescence imaging. Nonetheless, additional alterations at the level of the mitochondria discussed below may also impact the ability of aged granulosa cells to synthesize steroid hormones. Further work directly linking mitochondrial abnormalities specifically with altered steroidogenesis is needed.

\section{BI-DIRECTIONAL COMMUNICATION, ROLE FOR GAP JUNCTIONS IN FOLLICULAR METABOLISM}

Follicle growth and development is dependent upon bidirectional communication between the oocyte and the surrounding granulosa cells, which occurs through paracrine and juxtracrine signaling, the latter of which is maintained via gap junctions (Eppig, 1979; Lopez-Schier and St Johnston, 2001; Gittens et al., 2005; Su et al., 2008; Saadeldin et al., 2015). Gap junctions are oligomeric structures comprised of connexins which enable direct intercellular communication. First described by Anderson and Albertini (1976), gap junctions between the granulosa cells and developing oocytes were visualized by lanthanum tracer and freeze-fracture electron microscopy (EM). Gap junction-mediated communication between adjacent granulosa cells is modulated by connexin- 43 $(\mathrm{Cx} 43)$ gap junctions, whereas gap junctions between the granulosa cells and the oocyte are homotypic for connexin37 (Cx37), with Cx37 gap junctions creating a syncytial network between the two cell types (Kidder and Mhawi, 2002; Best et al., 2015). The oocyte has a low capacity for glucose metabolism, due in part to low phosphofructokinase activity (Cetica et al., 2002; Dumesic et al., 2015), while granulosa cells are largely glycolytic and supply pyruvate, along with amino acids and cholesterol, to the oocyte through Cx37 gap junctions (Anderson and Albertini, 1976; Gilula et al., 1978; Bornslaeger and Schultz, 1985). The mitochondria within the oocyte then convert the granulosa cell-derived pyruvate to acetyl CoA, which then enters the tricarboxylic acid (TCA) cycle and ETC to synthesize ATP (Sutton-McDowall et al., 2010). In a regulatory loop, the oocyte secretes paracrine factors, including Bone Morphogenetic Protein 15 (BMP15), Growth and Differentiation Factor 9 (GDF9), and Fibroblast Growth Factor 8 (FGF8), which coordinate to promote glycolysis in granulosa 


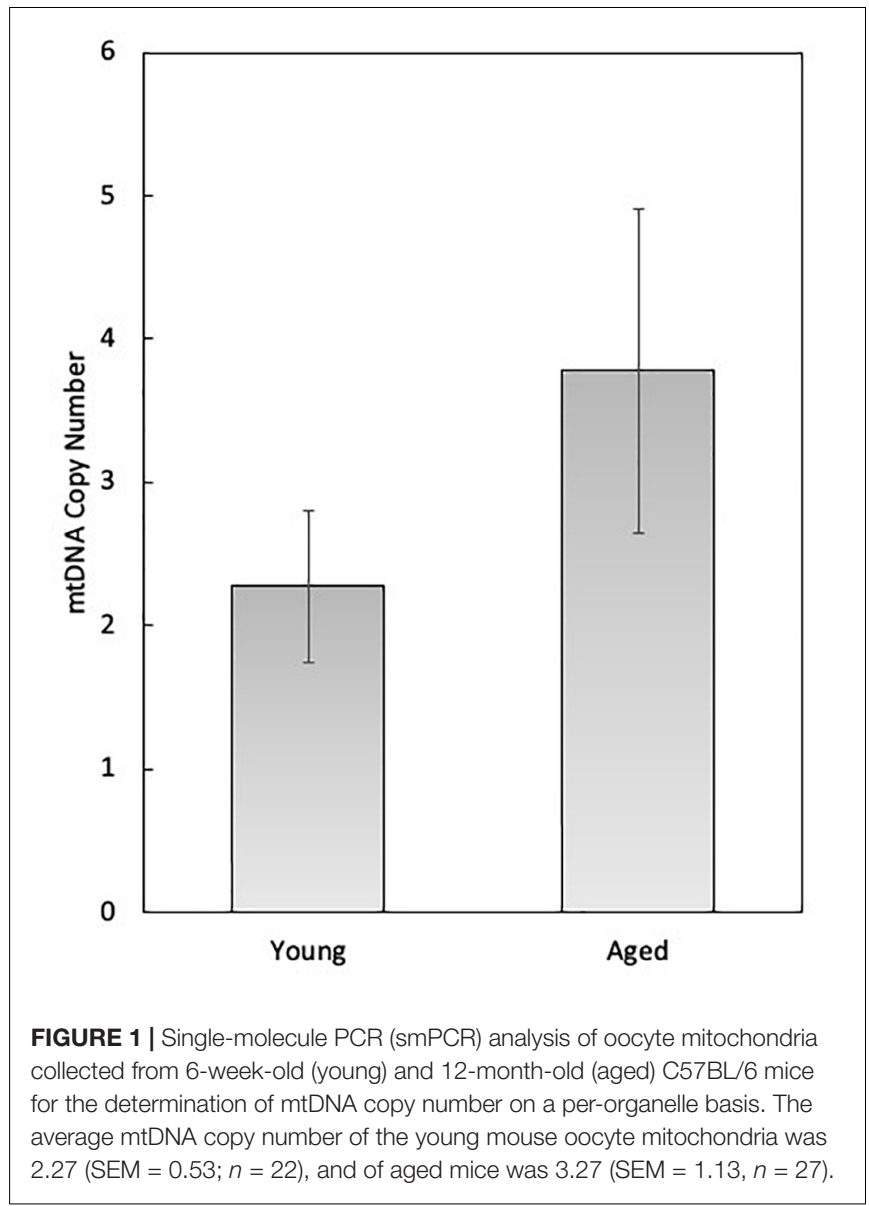

cells (Sugiura et al., 2007). In addition to resource sharing and maintenance of the oocyte-granulosa regulatory loop, diffusion of cGMP through Cx37 gap junctions of blocks the resumption of meiosis in immature follicles (Pincus and Enzmann, 1935; Downs and Eppig, 1987; Tornell et al., 1991; Carabatsos et al., 2000; Norris et al., 2009). Furthermore, it has recently been demonstrated using porcine cumulus-oocyte-complexes (COCs) that cumulus cells can utilize Cx37 gap junctions to deliver ATP to oocytes (Kansaku et al., 2017).

Gap junction communication between the oocyte and granulosa cells is made possible through transzonal projections (TZPs), which originate as filopodia from granulosa cells and process into the zona pellucida surrounding the oocyte (ElHayek et al., 2018). An electron micrograph of the granulosa cell-oocyte interface where TZPs are found has been included for reference (Figure 2). TZPs are not restricted to the granulosa cells immediately surrounding the oocyte, as imaging demonstrates that granulosa cells in distal layers extend long, actin-rich filaments to the oocyte (El-Hayek et al., 2018). Strikingly, recent analysis of $\mathrm{Cx} 43$ and $\mathrm{Cx} 37$ gap junctions on high pressure-frozen ovarian tissue using three-dimensional EM and immunogold detection has revealed gap junction internalization via connexosomes (Norris, 2021; Norris and Terasaki, 2021). Moreover, within Cx43 connexosomes mature organelles, including mitochondria and endosomes are visibly

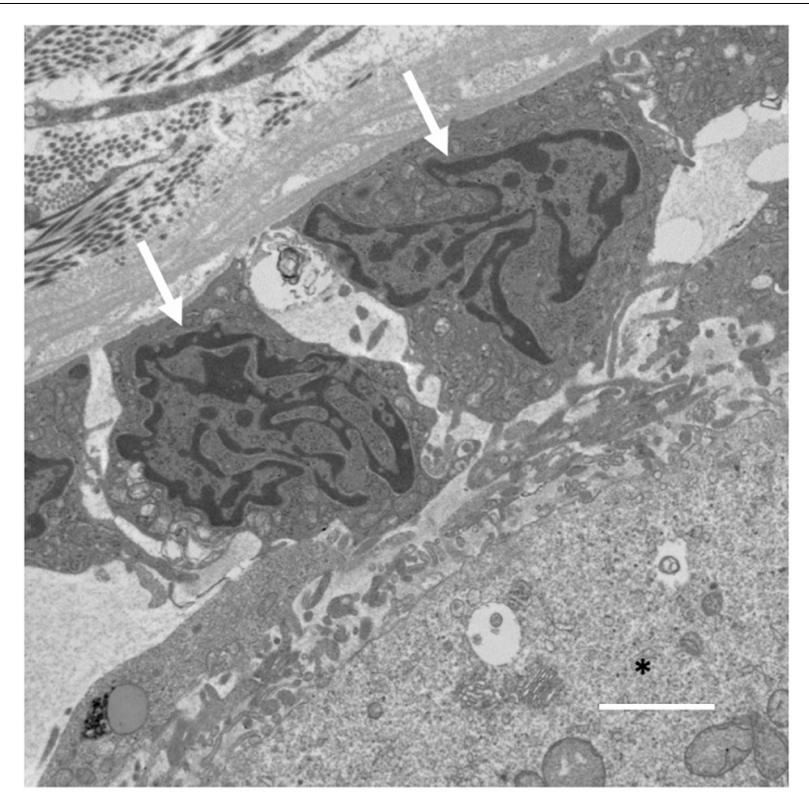

FIGURE 2 | Electron micrograph of an ovarian follicle at the oocyte-granulosa cell interface, with the oocyte identified using a black asterisk, and two granulosa cells identified with white arrows. Scale bar represents $2 \mu \mathrm{m}$.

observable, indicating cell-to-cell movement of organelles within the granulosa cell layer (Norris, 2021). Mitochondria can also be observed in deeply invaginated TZPs with Cx37-labeled gap junctions protruding into oocytes, implying the potential for mitochondrial transfer between granulosa cells and oocytes (Norris and Terasaki, 2021). Regulation of TZP formation by granulosa cells is facilitated by GDF9, one of the most wellcharacterized paracrine factors generated by oocytes. GDF9, signaling through the SMAD signaling pathway, upregulates the TZP-associated genes fascin homolog 1 (Fscn1), an actin bundling protein and myosin X (Myo10), an actin-based motor protein, both known to induce formation of filopodia (Bohil et al., 2006; Hashimoto et al., 2011; El-Hayek et al., 2018; Baena and Terasaki, 2019). With age, oocyte GDF9 expression declines (Li et al., 2014; Park et al., 2020; Gong et al., 2021) along with the expression of Fscn1 and Myo10, and the numbers of TZPs are reduced by approximately $40 \%$, resulting in a marked decrease in gap junctional communication between the oocyte and the granulosa cells (El-Hayek et al., 2018).

Recent work demonstrates a role for the OMM GTPase, mitofusin1 (MFN1) in regulation of follicle development and maintenance of the follicle reserve, which occurs, at least in part, though maintaining $\mathrm{Cx} 43$ and $\mathrm{Cx} 37$ gap junctions (Zhang et al., 2019). In mice null for $M f n\left(M f n^{-/-}\right)$, mRNA expression of both $C x 37$ and $C x 43$ were significantly decreased in oocytes and granulosa cells. A combination of both fluorescence microscopy and EM revealed a significant reduction in gap junctions and transzonal projections (TZPs), which, along with a reduction in expression of E-cadherin and N-cadherin, significantly impaired communication between the granulosa cells and the oocyte, inhibiting growth past the primary stage of development. 


\section{Young}

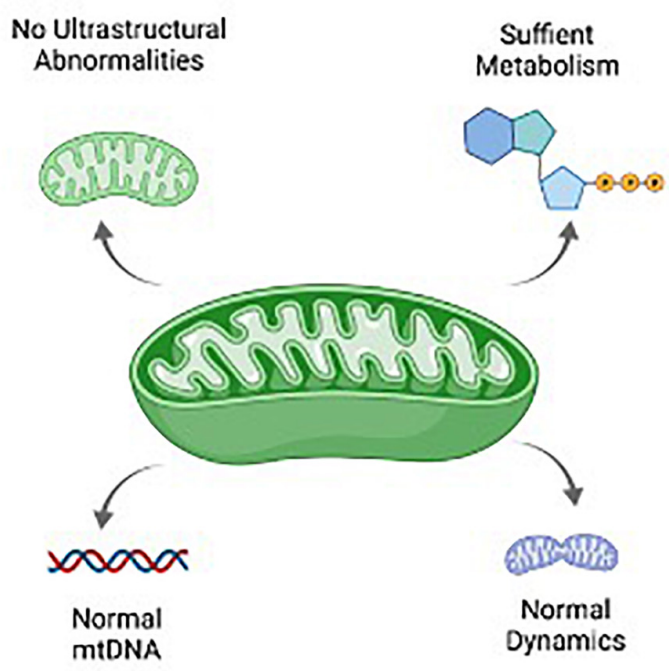

Aged

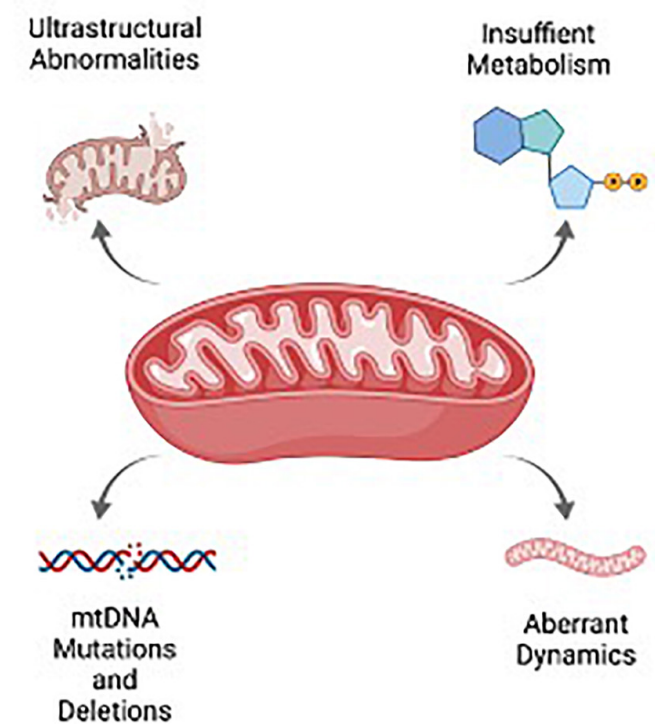

FIGURE 3 | Schematic overview of key mitochondrial characteristics that are negatively impacted by aging. These include mtDNA, mitochondrial ultrastructure and integrity, metabolism, and mitochondrial dynamics.

Notably, $\mathrm{Mfn}^{-/-}$mice showed an accumulation of ceramide, a membrane sphingolipid which accumulates on the OMM and is known to induce germ cell apoptosis, within oocytes (Perez et al., 2005). In aged mice, ceramide is trafficked through Cx37 gap junctions and plays a role in age-associated increased germ cell death through BCL2 Associated X, Apoptosis Regulator (Bax)-mediated apoptosis (Perez et al., 2005), a proapoptotic member of the B-cell lymphoma (Bcl-2) family of pro- and antiapoptotic factors associated with mitochondrial apoptosis (Tilly et al., 1997). Importantly, treatment with myriocin to inhibit de novo ceramide synthesis in $M \mathrm{Fn}^{-/-}$mice improved the growth of secondary follicles and formation of antral follicles, leading to a partial rescue of the reproductive phenotype (Zhang et al., 2019), indicating that in addition to mitochondrial-specific effects on gap junction communication, metabolic by-products associated with altered mitochondrial function may be important targets to improve oocyte quality.

As the oocyte is considered the orchestrator of oocytegranulosa cell communication, guiding the granulosa cells to produce factors to fulfill its needs throughout growth and folliculogenesis, it is perplexing why oocyte originating signals to sustain TZPs would decline. Perhaps this is to mitigate damage from the aging somatic environment, as aging granulosa cells may also have an impact on the decline in oocyte quality. Previous studies have collectively demonstrated that removal of the granulosa cell layer in aged female mice can have a positive impact on oocyte health and function. For example, Perez and Tilly demonstrated that removal of the granulosa/cumulus cell layer from eggs significantly reduced rates of apoptosis, essentially resulting in oocytes with a "youthful" phenotype (Perez and Tilly, 1997). How oocytes might be negatively influenced by the surrounding soma may involve circulating factors, the influence of an aging ovarian environment, as well as granulosa cells themselves.

\section{THE IMPACT OF AGE ON GRANULOSA CELL MITOCHONDRIA}

Many of the hallmarks associated with aging mitochondria in the soma impact granulosa cells in women of advance maternal age or in animal models for ovarian aging. These include abnormalities in mitochondrial ultrastructure and integrity, metabolism, dynamics, and mtDNA mutations and deletions (Figure 3). Such features appear to be a function of age, and are not dependent upon follicle development, as abnormal mitochondrial ultrastructure can be found in even the resting follicles of aged women. An analysis of ovarian tissue obtained from women of advanced maternal age tellingly revealed a high frequency of ruptured mitochondrial membranes in the granulosa cells when compared to a younger cohort, indicative of increased mitochondrial destruction with age (de Bruin et al., 2004). As follicles grow and the granulosa cells expand, these abnormal mitochondrial features are exacerbated. An analysis of luteinizing granulosa cells obtained from follicular aspirates revealed destruction of mitochondrial membrane integrity, lack of cristae density, and vacuolization of the cristae and mitochondrial matrix with age (Tatone et al., 2006), while those obtained from a younger patient cohort had mitochondrial cristae with a tubular phenotype, which is notably associated with high steroidogenic activity (Rotmensch et al., 1986; Tatone et al., 2006). 
The accrual of atypical mitochondrial ultrastructure in aged granulosa cells as they progress through follicle development may also be attributed to increasing reactive oxygen species (ROS), detectable in follicular fluid samples. With age, key genes associated with the neutralization of ROS, including superoxide dismutase 1 (SOD1), SOD2, and catalase, are reduced, indicative of impaired ROS scavenging activity. This has important implications, as SOD1 and 2 expression is elevated in response to oxidative stress and inflammation, both of which are associated with the ovulatory response (Espey, 1980), with antiinflammatory medications reported to inhibit ovulation (Espey et al., 1982). Moreover, ovulation itself has been shown to be dependent upon $\mathrm{LH}$-induced ROS production, with $\mathrm{H}_{2} \mathrm{O}_{2}$ capable of mimicking LH-induced cumulus expansion, and ablation of ROS blocking genes critical for ovulation (Shkolnik et al., 2011). It has been noted that the expression pattern of SOD1 is identical to that of HSD3 $\beta 1$ (Sugino, 2005), and that dehydrogenation of pregnenolone to form progesterone may be dependent upon SOD1 (Agrawal and Laloraya, 1977). In Sod1-deficient female mice, levels of progesterone fall far below those of WT mice, even following superovulation (Noda et al., 2012). Furthermore, superoxide significantly impairs $\Delta \psi_{\mathrm{m}}$ in the absence of SOD1, resulting in severe mitochondrial damage (Aquilano et al., 2006), and is consistent with the reduced $\Delta \psi_{\mathrm{m}}$ observed in women of advanced maternal age (Liu et al., 2017). Therefore, the declining levels of ROS scavengers with age may have profound impacts on granulosa cell function, from accelerated damage due to ROS to reduced steroidogenic capacity.

Additionally, the link between accumulating ROS and mtDNA damage, deletions, and mutations as they occur with age is well known (Loeb et al., 2005). It has been posited that mtDNA content of cumulus cells may be a non-invasive prognostic for embryo quality (Diez-Juan et al., 2015; Fragouli et al., 2015; Desquiret-Dumas et al., 2017), although this has been experimentally questioned (Victor et al., 2017). More recent evidence based on quantitative PCR to evaluate the ratio of mtDNA:nDNA indicates that mtDNA content of cumulus cells is negatively correlated with age, and further supports the finding that mtDNA content of cumulus cells may be considered as a biomarker for IVF outcomes (Yang et al., 2021). In addition to a decline in mtDNA copy number with age, the propensity for

\section{REFERENCES}

Agrawal, P., and Laloraya, M. M. (1977). Induction of peroxidase in corpora lutea of rat ovary by lutropin. Biochem. J. 166, 205-208. doi: 10.1042/bj1660205

Allen, J. A., Shankara, T., Janus, P., Buck, S., Diemer, T., Hales, K. H., et al. (2006). Energized, polarized, and actively respiring mitochondria are required for acute Leydig cell steroidogenesis. Endocrinology 147, 3924-3935. doi: 10.1210/en. 2005- 1204

Anderson, E., and Albertini, D. F. (1976). Gap junctions between the oocyte and companion follicle cells in the mammalian ovary. J. Cell Biol. 71, 680-686. doi: $10.1083 /$ jcb.71.2.680

Annis, S., Fleischmann, Z., Khrapko, M., Franco, M., Wasko, K., Woods, D., et al. (2019). Quasi-Mendelian paternal inheritance of mitochondrial DNA: a notorious artifact, or anticipated behavior? Proc. Natl. Acad. Sci. U.S.A. 116, 14797-14798. doi: 10.1073/pnas. 1821436116 granulosa cells to acquire mutations and deletions with age has been examined. In a study evaluating the so called "common deletion" which is a 4,977 bp deletion of mitochondrial DNA $\left(\Delta \mathrm{mtDNA}^{4977}\right.$ ), with an early study concluded that the frequency of $\Delta \mathrm{mtDNA}^{4977}$ in granulosa increases with age (Seifer et al., 2002). However, more recent work with a larger patient cohort suggests that age does not appear to be a factor in the frequency of this deletion in mural granulosa or cumulus cells (Au et al., 2005; Chan et al., 2006). The latter conclusion has been further supported, with recent evidence also indicating that while there does not appear to be a correlation between $\Delta \mathrm{mtDNA}^{4977}$ and age, $\Delta \mathrm{mtDNA}^{4977}$ is associated with granulosa cell apoptosis (Au et al., 2005). Advances in sequencing platforms, such as Long-molecule UMI-driven Consensus Sequencing (LUCS), will enable more detailed analysis of the mitochondrial mutations and damage that might occur with age (Annis et al., 2020).

\section{CONCLUSION}

Granulosa cells are critical for ovarian function, including steroid hormone biosynthesis and as cooperative partners for oocyte growth and maturation. Therefore, it is not surprising that there has been an interest in evaluating the mitochondria of granulosa and cumulus cells as biomarkers for ovarian function, including oocyte and embryo quality. Intriguingly, recent evidence suggests cell-free mtDNA is released into the follicular fluid, presumably by granulosa or cumulus cells, and that this may potentially be used as a non-invasive biomarker for oocyte quality (Huo et al., 2020). Additional work on mitochondrial properties, dynamics, and function will likely reveal new and important details on the biological significance of these findings. Moreover, as technological advances in DNA sequencing and metabolomics continue to improve, further evaluation of how granulosa cells may act as effectors, positive and negative, of oocyte function can be addressed.

\section{AUTHOR CONTRIBUTIONS}

HA and DW wrote the manuscript. Both authors contributed to the article and approved the submitted version.

Annis, S., Fleischmann, Z., Logan, R., Mullin-Bernstein, Z., Franco, M., Saurich, J., et al. (2020). LUCS: a high-resolution nucleic acid sequencing tool for accurate long-read analysis of individual DNA molecules. Aging 12, 7603-7613. doi: 10.18632/aging.103171

Aquilano, K., Vigilanza, P., Rotilio, G., and Ciriolo, M. R. (2006). Mitochondrial damage due to SOD1 deficiency in SH-SY5Y neuroblastoma cells: a rationale for the redundancy of SOD1. FASEB J. 20, 1683-1685. doi: 10.1096/fj.05-5225fje

Artemenko, I. P., Zhao, D., Hales, D. B., Hales, K. H., and Jefcoate, C. R. (2001). Mitochondrial processing of newly synthesized steroidogenic acute regulatory protein (StAR), but not total StAR, mediates cholesterol transfer to cytochrome P450 side chain cleavage enzyme in adrenal cells. J. Biol. Chem. 276, 4658346596. doi: 10.1074/jbc.M107815200

Au, H. K., Lin, S. H., Huang, S. Y., Yeh, T. S., Tzeng, C. R., and Hsieh, R. H. (2005). Deleted mitochondrial DNA in human luteinized granulosa cells. Ann. N. Y. Acad. Sci. 1042, 136-141. doi: 10.1196/annals.1338.014 
Baena, V., and Terasaki, M. (2019). Three-dimensional organization of transzonal projections and other cytoplasmic extensions in the mouse ovarian follicle. Sci. Rep. 9:1262. doi: 10.1038/s41598-018-37766-2

Battaglia, D. E., Goodwin, P., Klein, N. A., and Soules, M. R. (1996). Influence of maternal age on meiotic spindle assembly in oocytes from naturally cycling women. Hum. Reprod. 11, 2217-2222. doi: 10.1093/oxfordjournals.humrep. a019080

Baughman, J. M., Perocchi, F., Girgis, H. S., Plovanich, M., Belcher-Timme, C. A., Sancak, Y., et al. (2011). Integrative genomics identifies MCU as an essential component of the mitochondrial calcium uniporter. Nature 476, 341-345. doi: 10.1038 /nature10234

Bentov, Y., Yavorska, T., Esfandiari, N., Jurisicova, A., and Casper, R. F. (2011). The contribution of mitochondrial function to reproductive aging. J. Assist. Reprod. Genet. 28, 773-783. doi: 10.1007/s10815-011-9588-7

Bertoldo, M. J., Listijono, D. R., Ho, W. J., Riepsamen, A. H., Goss, D. M., Richani, D., et al. (2020). NAD (+) repletion rescues female fertility during reproductive aging. Cell Rep. 30, 1670-1681.e7. doi: 10.1016/j.celrep.2020.01.058

Best, M. W., Wu, J., Pauli, S. A., Kane, M. A., Pierzchalski, K., Session, D. R., et al. (2015). A role for retinoids in human oocyte fertilization: regulation of connexin 43 by retinoic acid in cumulus granulosa cells. Mol. Hum. Reprod. 21, 527-534. doi: 10.1093/molehr/gav017

Bohil, A. B., Robertson, B. W., and Cheney, R. E. (2006). Myosin-X is a molecular motor that functions in filopodia formation. Proc. Natl. Acad. Sci. U.S.A. 103, 12411-12416. doi: 10.1073/pnas.0602443103

Bornslaeger, E. A., and Schultz, R. M. (1985). Regulation of mouse oocyte maturation: effect of elevating cumulus cell cAMP on oocyte cAMP levels. Biol. Reprod. 33, 698-704. doi: 10.1095/biolreprod33.3.698

Boucret, L., Chao de la Barca, J. M., Moriniere, C., Desquiret, V., Ferre-L'Hotellier, V., Descamps, P., et al. (2015). Relationship between diminished ovarian reserve and mitochondrial biogenesis in cumulus cells. Hum. Reprod. 30, 1653-1664. doi: 10.1093/humrep/dev114

Boudoures, A. L., Saben, J., Drury, A., Scheaffer, S., Modi, Z., Zhang, W., et al. (2017). Obesity-exposed oocytes accumulate and transmit damaged mitochondria due to an inability to activate mitophagy. Dev. Biol. 426, 126-138. doi: 10.1016/j.ydbio.2017.04.005

Carabatsos, M. J., Sellitto, C., Goodenough, D. A., and Albertini, D. F. (2000). Oocyte-granulosa cell heterologous gap junctions are required for the coordination of nuclear and cytoplasmic meiotic competence. Dev. Biol 226, 167-179. doi: 10.1006/dbio.2000.9863

Cetica, P., Pintos, L., Dalvit, G., and Beconi, M. (2002). Activity of key enzymes involved in glucose and triglyceride catabolism during bovine oocyte maturation in vitro. Reproduction 124, 675-681. doi: 10.1530/reprod/124.5.675

Chan, C. C., Liu, V. W., Lau, E. Y., Yeung, W. S., Ng, E. H., and Ho, P. C. (2006). Mitochondrial DNA deletion in granulosa and cumulus oophorus cells. Fertil. Steril. 85, 780-782. doi: 10.1016/j.fertnstert.2005.08.042

de Bruin, J. P., Dorland, M., Spek, E. R., Posthuma, G., van Haaften, M., Looman, C. W., et al. (2004). Age-related changes in the ultrastructure of the resting follicle pool in human ovaries. Biol. Reprod 70, 419-424. doi: 10.1095/ biolreprod.103.015784

Desquiret-Dumas, V., Clement, A., Seegers, V., Boucret, L., Ferre-L'Hotellier, V., Bouet, P. E., et al. (2017). The mitochondrial DNA content of cumulus granulosa cells is linked to embryo quality. Hum. Reprod. 32, 607-614. doi: 10.1093/humrep/dew341

Diez-Juan, A., Rubio, C., Marin, C., Martinez, S., Al-Asmar, N., Riboldi, M., et al. (2015). Mitochondrial DNA content as a viability score in human euploid embryos: less is better. Fertil. Steril. 104, 534-41.e1. doi: 10.1016/j.fertnstert. 2015.05.022

Downs, S. M., and Eppig, J. J. (1987). Induction of mouse oocyte maturation in vivo by perturbants of purine metabolism. Biol. Reprod. 36, 431-437. doi: 10.1095/biolreprod36.2.431

Dumesic, D. A., Meldrum, D. R., Katz-Jaffe, M. G., Krisher, R. L., and Schoolcraft, W. B. (2015). Oocyte environment: follicular fluid and cumulus cells are critical for oocyte health. Fertil. Steril. 103, 303-316. doi: 10.1016/j.fertnstert.2014.11. 015

Eichenlaub-Ritter, U., Vogt, E., Yin, H., and Gosden, R. (2004). Spindles, mitochondria and redox potential in ageing oocytes. Reprod. Biomed. Online 8, 45-58. doi: 10.1016/s1472-6483(10)60497-x
El-Hayek, S., Yang, Q., Abbassi, L., FitzHarris, G., and Clarke, H. J. (2018). Mammalian oocytes locally remodel follicular architecture to provide the foundation for germline-soma communication. Curr. Biol. 28, 1124-1131.e3. doi: 10.1016/j.cub.2018.02.039

Eppig, J. J. (1979). A comparison between oocyte growth in coculture with granulosa cells and oocytes with granulosa cell-oocyte junctional contact maintained in vitro. J. Exp. Zool. 209, 345-353. doi: 10.1002/jez.1402090216

Eppig, J. J., Wigglesworth, K., and Pendola, F. L. (2002). The mammalian oocyte orchestrates the rate of ovarian follicular development. Proc. Natl. Acad. Sci. U.S.A. 99, 2890-2894. doi: 10.1073/pnas.052658699

Espey, L. L. (1980). Ovulation as an inflammatory reaction-a hypothesis. Biol. Reprod. 22, 73-106. doi: 10.1095/biolreprod22.1.73

Espey, L. L., Stein, V. I., and Dumitrescu, J. (1982). Survey of antiinflammatory agents and related drugs as inhibitors of ovulation in the rabbit. Fertil. Steril. 38 , 238-247. doi: 10.1016/s0015-0282(16)46466-6

Faraci, C., Annis, S., Jin, J., Li, H., Khrapko, K., and Woods, D. C. (2018). Impact of exercise on oocyte quality in the POLG mitochondrial DNA mutator mouse. Reproduction 156, 185-194. doi: 10.1530/REP-18-0061

Feuerstein, P., Cadoret, V., Dalbies-Tran, R., Guerif, F., Bidault, R., and Royere, D. (2007). Gene expression in human cumulus cells: one approach to oocyte competence. Hum. Reprod. 22, 3069-3077. doi: 10.1093/humrep/dem336

Fragouli, E., Spath, K., Alfarawati, S., Kaper, F., Craig, A., Michel, C. E., et al. (2015). Altered levels of mitochondrial DNA are associated with female age, aneuploidy, and provide an independent measure of embryonic implantation potential. PLoS Genet. 11:e1005241. doi: 10.1371/journal.pgen.1005241

Friedman, J. R., and Nunnari, J. (2014). Mitochondrial form and function. Nature 505, 335-343. doi: 10.1038/nature 12985

Gilula, N. B., Epstein, M. L., and Beers, W. H. (1978). Cell-to-cell communication and ovulation. A study of the cumulus-oocyte complex. J. Cell Biol. 78, 58-75. doi: $10.1083 /$ jcb.78.1.58

Gittens, J. E., Barr, K. J., Vanderhyden, B. C., and Kidder, G. M. (2005). Interplay between paracrine signaling and gap junctional communication in ovarian follicles. J. Cell Sci. 118, 113-122. doi: 10.1242/jcs.01587

Gong, Y., Li-Ling, J., Xiong, D., Wei, J., Zhong, T., and Tan, H. (2021). Agerelated decline in the expression of GDF9 and BMP15 genes in follicle fluid and granulosa cells derived from poor ovarian responders. J. Ovarian Res. 14:1. doi: 10.1186/s13048-020-00757-x

Gray, M. W. (2012). Mitochondrial evolution. Cold Spring Harb. Perspect. Biol. 4:a011403.

Hamel, M., Dufort, I., Robert, C., Gravel, C., Leveille, M. C., Leader, A., et al. (2008). Identification of differentially expressed markers in human follicular cells associated with competent oocytes. Hum. Reprod. 23, 1118-1127. doi: 10.1093/humrep/den048

Hashimoto, Y., Kim, D. J., and Adams, J. C. (2011). The roles of fascins in health and disease. J. Pathol. 224, 289-300. doi: 10.1002/path.2894

Hassold, T., and Chiu, D. (1985). Maternal age-specific rates of numerical chromosome abnormalities with special reference to trisomy. Hum. Genet. 70, 11-17. doi: 10.1007/BF00389450

Henderson, S. A., and Edwards, R. G. (1968). Chiasma frequency and maternal age in mammals. Nature 218, 22-28. doi: 10.1038/218022a0

Hirshfield, A. N., and DeSanti, A. M. (1995). Patterns of ovarian cell proliferation in rats during the embryonic period and the first three weeks postpartum. Biol. Reprod. 53, 1208-1221. doi: 10.1095/biolreprod53.5.1208

Hook, E. B. (1981). Rates of chromosome abnormalities at different maternal ages. Obstet. Gynecol. 58, 282-285.

Hunt, P. A., and Hassold, T. J. (2008). Human female meiosis: what makes a good egg go bad? Trends Genet. 24, 86-93. doi: 10.1016/j.tig.2007.11.010

Huo, P., Zhang, N., Zhang, P., and Wu, X. (2020). The levels of follicular fluid cellfree mitochondrial DNA could serve as a biomarker for pregnancy success in patients with small ovarian endometriosis cysts: a case-control study. Medicine 99:e23348. doi: 10.1097/MD.0000000000023348

Huttemann, M., Lee, I., Pecinova, A., Pecina, P., Przyklenk, K., and Doan, J. W. (2008). Regulation of oxidative phosphorylation, the mitochondrial membrane potential, and their role in human disease. J. Bioenerg. Biomembr. 40, 445-456. doi: 10.1007/s10863-008-9169-3

Jamnongjit, M., and Hammes, S. R. (2006). Ovarian steroids: the good, the bad, and the signals that raise them. Cell Cycle 5, 1178-1183. doi: 10.4161/cc.5.11.2803 
Kansaku, K., Itami, N., Kawahara-Miki, R., Shirasuna, K., Kuwayama, T., and Iwata, H. (2017). Differential effects of mitochondrial inhibitors on porcine granulosa cells and oocytes. Theriogenology 103, 98-103. doi: 10.1016/j. theriogenology.2017.07.049

Karuputhula, N. B., Chattopadhyay, R., Chakravarty, B., and Chaudhury, K. (2013). Oxidative status in granulosa cells of infertile women undergoing IVF. Syst. Biol. Reprod. Med. 59, 91-98. doi: 10.3109/19396368.2012.743197

Kidder, G. M., and Mhawi, A. A. (2002). Gap junctions and ovarian folliculogenesis. Reproduction 123, 613-620. doi: 10.1530/reprod/123.5.613

Kidder, G. M., and Vanderhyden, B. C. (2010). Bidirectional communication between oocytes and follicle cells: ensuring oocyte developmental competence. Can. J. Physiol. Pharmacol. 88, 399-413. doi: 10.1139/y10-009

Kiriakidou, M., McAllister, J. M., Sugawara, T., and Strauss, J. F. III (1996). Expression of steroidogenic acute regulatory protein (StAR) in the human ovary. J. Clin. Endocrinol. Metab. 81, 4122-4128. doi: 10.1210/jcem.81.11. 8923870

Li, Y., Li, R. Q., Ou, S. B., Zhang, N. F., Ren, L., Wei, L. N., et al. (2014). Increased GDF9 and BMP15 mRNA levels in cumulus granulosa cells correlate with oocyte maturation, fertilization, and embryo quality in humans. Reprod. Biol. Endocrinol. 12:81. doi: 10.1186/1477-7827-12-81

Liu, M. J., Sun, A. G., Zhao, S. G., Liu, H., Ma, S. Y., Li, M., et al. (2018). Resveratrol improves in vitro maturation of oocytes in aged mice and humans. Fertil. Steril. 109, 900-907. doi: 10.1016/j.fertnstert.2018.01.020

Liu, Y., Han, M., Li, X., Wang, H., Ma, M., Zhang, S., et al. (2017). Age-related changes in the mitochondria of human mural granulosa cells. Hum. Reprod. 32, 2465-2473. doi: 10.1093/humrep/dex309

Loeb, L. A., Wallace, D. C., and Martin, G. M. (2005). The mitochondrial theory of aging and its relationship to reactive oxygen species damage and somatic mtDNA mutations. Proc. Natl. Acad. Sci. U.S.A. 102, 18769-18770. doi: 10. 1073/pnas.0509776102

Lopez-Schier, H., and St Johnston, D. (2001). Delta signaling from the germ line controls the proliferation and differentiation of the somatic follicle cells during Drosophila oogenesis. Genes Dev. 15, 1393-1405. doi: 10.1101/gad.200901

Luo, S., Valencia, C. A., Zhang, J., Lee, N. C., Slone, J., Gui, B., et al. (2018). Biparental inheritance of mitochondrial DNA in humans. Proc. Natl. Acad. Sci. U.S.A. 115, 13039-13044.

MacDonald, J. A., Fowle, W. H., and Woods Ph, D. D. (2017). New insights on mitochondrial heterogeneity observed in prepared mitochondrial samples following a method for freeze-fracture and scanning electron microscopy. Micron 101, 25-31. doi: 10.1016/j.micron.2017.05.002

Miller, W. L. (2013). Steroid hormone synthesis in mitochondria. Mol. Cell Endocrinol. 379, 62-73. doi: 10.1016/j.mce.2013.04.014

Miller, W. L. (2017). Disorders in the initial steps of steroid hormone synthesis. J. Steroid Biochem. Mol. Biol. 165, 18-37. doi: 10.1016/j.jsbmb.2016.03.009

Mitchell, P. (1961). Coupling of phosphorylation to electron and hydrogen transfer by a chemi-osmotic type of mechanism. Nature 191, 144-148. doi: 10.1038/ $191144 \mathrm{a} 0$

Muhammad, F., Yivgi-Ohana, N., Shveiky, D., Orly, J., Alexander, S., and Laufer, N. (2009). Levels of steroidogenic acute regulatory protein and mitochondrial membrane potential in granulosa cells of older poor-responder women. Fertil. Steril. 91, 220-225. doi: 10.1016/j.fertnstert.2007.10.027

Noda, Y., Ota, K., Shirasawa, T., and Shimizu, T. (2012). Copper/zinc superoxide dismutase insufficiency impairs progesterone secretion and fertility in female mice. Biol. Reprod. 86, 1-8. doi: 10.1095/biolreprod.111.09 2999

Norris, R. P. (2021). Transfer of mitochondria and endosomes between cells by gap junction internalization. Traffic 22, 174-179. doi: 10.1111/tra.12786

Norris, R. P., and Terasaki, M. (2021). Gap junction internalization and processing in vivo: a 3D immuno-electron microscopy study. J. Cell Sci. 134:jcs252726. doi: $10.1242 /$ jcs. 252726

Norris, R. P., Ratzan, W. J., Freudzon, M., Mehlmann, L. M., Krall, J., Movsesian, M. A., et al. (2009). Cyclic GMP from the surrounding somatic cells regulates cyclic AMP and meiosis in the mouse oocyte. Development 136, 1869-1878. doi: $10.1242 /$ dev.035238

Ogino, M., Tsubamoto, H., Sakata, K., Oohama, N., Hayakawa, H., Kojima, T., et al. (2016). Mitochondrial DNA copy. J. Assist. Reprod. Genet. 33, 367-371.

Ostuni, A., Faruolo, M. P., Sileo, C., Petillo, A., and Boni, R. (2018). Effect of follicle size and atresia grade on mitochondrial membrane potential and steroidogenic acute regulatory protein expression in bovine granulosa cells. Zygote 26, 476-484. doi: 10.1017/S0967199418000564

Pan, H., Ma, P., Zhu, W., and Schultz, R. M. (2008). Age-associated increase in aneuploidy and changes in gene expression in mouse eggs. Dev. Biol. 316, 397-407. doi: 10.1016/j.ydbio.2008.01.048

Park, M. J., Ahn, J. W., Kim, K. H., Bang, J., Kim, S. C., Jeong, J. Y., et al. (2020). Prediction of ovarian aging using ovarian expression of BMP15, GDF9, and C-KIT. Exp. Biol. Med. 245, 711-719. doi: 10.1177/1535370220915826

Perez, G. I., and Tilly, J. L. (1997). Cumulus cells are required for the increased apoptotic potential in oocytes of aged mice. Hum. Reprod. 12, 2781-2783. doi: $10.1093 /$ humrep/12.12.2781

Perez, G. I., Jurisicova, A., Matikainen, T., Moriyama, T., Kim, M. R., Takai, Y., et al. (2005). A central role for ceramide in the age-related acceleration of apoptosis in the female germline. FASEB J. 19, 860-862. doi: 10.1096/fj.04-2903fje

Perry, S. W., Norman, J. P., Barbieri, J., Brown, E. B., and Gelbard, H. A. (2011). Mitochondrial membrane potential probes and the proton gradient: a practical usage guide. Biotechniques 50, 98-115. doi: 10.2144/000113610

Piko, L., and Matsumoto, L. (1976). Number of mitochondria and some properties of mitochondrial DNA in the mouse egg. Dev. Biol. 49, 1-10. doi: 10.1016/00121606(76)90253-0

Pincus, G., and Enzmann, E. V. (1935). The Comparative behavior of mammalian eggs in vivo and in vitro : I. the activation of ovarian eggs. J. Exp. Med. 62, 665-675. doi: 10.1084/jem.62.5.665

Rotmensch, S., Dor, J., Furman, A., Rudak, E., Mashiach, S., and Amsterdam, A. (1986). Ultrastructural characterization of human granulosa cells in stimulated cycles: correlation with oocyte fertilizability. Fertil. Steril. 45, 671-679. doi: 10.1016/s0015-0282(16)49340-4

Saadeldin, I. M., Elsayed, A., Kim, S. J., Moon, J. H., and Lee, B. C. (2015). A spatial model showing differences between juxtacrine and paracrine mutual oocyte-granulosa cells interactions. Indian J. Exp. Biol. 53, 75-81.

Seifer, D. B., DeJesus, V., and Hubbard, K. (2002). Mitochondrial deletions in luteinized granulosa cells as a function of age in women undergoing in vitro fertilization. Fertil. Steril. 78, 1046-1048. doi: 10.1016/s0015-0282(02)04214-0

Selesniemi, K., Lee, H. J., Muhlhauser, A., and Tilly, J. L. (2011). Prevention of maternal aging-associated oocyte aneuploidy and meiotic spindle defects in mice by dietary and genetic strategies. Proc. Natl. Acad. Sci. U.S.A. 108, 12319-12324. doi: 10.1073/pnas.1018793108

Shkolnik, K., Tadmor, A., Ben-Dor, S., Nevo, N., Galiani, D., and Dekel, N. (2011). Reactive oxygen species are indispensable in ovulation. Proc. Natl. Acad. Sci. U.S.A. 108, 1462-1467. doi: 10.1073/pnas.1017213108

Smith, M. F., McIntush, E. W., and Smith, G. W. (1994). Mechanisms associated with corpus luteum development. J. Anim. Sci. 72, 1857-1872. doi: 10.2527/ 1994.7271857x

Sreerangaraja Urs, D. B., Wu, W. H., Komrskova, K., Postlerova, P., Lin, Y. F., Tzeng, C. R., et al. (2020). Mitochondrial function in modulating human granulosa cell steroidogenesis and female fertility. Int. J. Mol. Sci. 21:3592. doi: $10.3390 / \mathrm{ijms} 21103592$

Stocco, D. M. (2001). StAR protein and the regulation of steroid hormone biosynthesis. Annu. Rev. Physiol. 63, 193-213. doi: 10.1146/annurev.physiol.63. 1.193

Su, Y. Q., Sugiura, K., Wigglesworth, K., O’Brien, M. J., Affourtit, J. P., Pangas, S. A., et al. (2008). Oocyte regulation of metabolic cooperativity between mouse cumulus cells and oocytes: BMP15 and GDF9 control cholesterol biosynthesis in cumulus cells. Development 135, 111-121. doi: 10.1242/dev.009068

Sugino, N. (2005). Reactive oxygen species in ovarian physiology. Reprod. Med. Biol. 4, 31-44. doi: 10.1007/BF03016135

Sugiura, K., Su, Y. Q., Diaz, F. J., Pangas, S. A., Sharma, S., Wigglesworth, K., et al. (2007). Oocyte-derived BMP15 and FGFs cooperate to promote glycolysis in cumulus cells. Development 134, 2593-2603. doi: 10.1242/dev.006882

Sutton-McDowall, M. L., Gilchrist, R. B., and Thompson, J. G. (2010). The pivotal role of glucose metabolism in determining oocyte developmental competence. Reproduction 139, 685-695. doi: 10.1530/REP-09-0345

Tarin, J. J., Perez-Albala, S., and Cano, A. (2001). Cellular and morphological traits of oocytes retrieved from aging mice after exogenous ovarian stimulation. Biol. Reprod. 65, 141-150. doi: 10.1095/biolreprod65.1.141

Tarin, J. J., Perez-Albala, S., and Cano, A. (2002). Oral antioxidants counteract the negative effects of female aging on oocyte quantity and quality in the mouse. Mol. Reprod. Dev. 61, 385-397. doi: 10.1002/mrd.10041 
Tatone, C., Carbone, M. C., Falone, S., Aimola, P., Giardinelli, A., Caserta, D., et al. (2006). Age-dependent changes in the expression of superoxide dismutases and catalase are associated with ultrastructural modifications in human granulosa cells. Mol. Hum. Reprod. 12, 655-660. doi: 10.1093/molehr/gal080

Tatone, C., Heizenrieder, T., Di Emidio, G., Treffon, P., Amicarelli, F., Seidel, T., et al. (2011). Evidence that carbonyl stress by methylglyoxal exposure induces DNA damage and spindle aberrations, affects mitochondrial integrity in mammalian oocytes and contributes to oocyte ageing. Hum. Reprod. 26, 1843-1859. doi: 10.1093/humrep/der140

Tilly, J. L., Tilly, K. I., and Perez, G. I. (1997). The genes of cell death and cellular susceptibility to apoptosis in the ovary: a hypothesis. Cell Death Differ. 4, 180-187. doi: 10.1038/sj.cdd.4400238

Tornell, J., Billig, H., and Hillensjo, T. (1991). Regulation of oocyte maturation by changes in ovarian levels of cyclic nucleotides. Hum. Reprod. 6, 411-422. doi: 10.1093/oxfordjournals.humrep.a137351

Truman, A. M., Tilly, J. L., and Woods, D. C. (2017). Ovarian regeneration: the potential for stem cell contribution in the postnatal ovary to sustained endocrine function. Mol. Cell Endocrinol. 445, 74-84. doi: 10.1016/j.mce.2016. 10.012

Tsukamoto, S., Kuma, A., and Mizushima, N. (2008). The role of autophagy during the oocyte-to-embryo transition. Autophagy 4, 1076-1078. doi: 10.4161/auto. 7065

Victor, A. R., Brake, A. J., Tyndall, J. C., Griffin, D. K., Zouves, C. G., Barnes, F. L., et al. (2017). Accurate quantitation of mitochondrial DNA reveals uniform levels in human blastocysts irrespective of ploidy, age, or implantation potential. Fertil. Steril. 107, 34-42e3. doi: 10.1016/j.fertnstert.2016.09.028

Wai, T., Ao, A., Zhang, X., Cyr, D., Dufort, D., and Shoubridge, E. A. (2010). The role of mitochondrial DNA copy number in mammalian fertility. Biol. Reprod. 83, 52-62. doi: 10.1095/biolreprod.109.080887

Wathlet, S., Adriaenssens, T., Segers, I., Verheyen, G., Janssens, R., Coucke, W., et al. (2012). New candidate genes to predict pregnancy outcome in single embryo transfer cycles when using cumulus cell gene expression. Fertil. Steril. 98, e1-e4. doi: 10.1016/j.fertnstert.2012.05.007

Wigglesworth, K., Lee, K. B., O’Brien, M. J., Peng, J., Matzuk, M. M., and Eppig, J. J. (2013). Bidirectional communication between oocytes and ovarian follicular somatic cells is required for meiotic arrest of mammalian oocytes. Proc. Natl. Acad. Sci. U.S.A. 110, E3723-E3729. doi: 10.1073/pnas.1314829110

Woods, D. C. (2017). Mitochondrial heterogeneity: evaluating mitochondrial subpopulation dynamics in stem cells. Stem Cells Int. 2017:7068567. doi: 10. $1155 / 2017 / 7068567$
Woods, D. C., and Tilly, J. L. (2015). Autologous Germline Mitochondrial Energy Transfer (AUGMENT) in human assisted reproduction. Semin. Reprod. Med. 33, 410-421. doi: 10.1055/s-0035-1567826

Woods, D. C., Khrapko, K., and Tilly, J. L. (2018). Influence of maternal aging on mitochondrial heterogeneity, inheritance, and function in oocytes and preimplantation embryos. Genes 9:265. doi: 10.3390/genes905 0265

Yang, S. C., Yu, E. J., Park, J. K., Kim, T. H., Eum, J. H., Paek, S. K., et al. (2021). The ratio of mitochondrial DNA to genomic DNA copy number in cumulus cell may serve as a biomarker of embryo quality in IVF cycles. Reprod. Sci. 28, 2495-2502. doi: 10.1007/s43032-021-00532-3

Yazawa, T., Imamichi, Y., Sekiguchi, T., Miyamoto, K., Uwada, J., Khan, M. R. I., et al. (2019). Transcriptional regulation of ovarian steroidogenic genes: recent findings obtained from stem cell-derived steroidogenic cells. Biomed. Res. Int. 2019:8973076. doi: 10.1155/2019/8973076

Zhang, M., Bener, M. B., Jiang, Z., Wang, T., Esencan, E., Scott Iii, R., et al. (2019). Mitofusin 1 is required for female fertility and to maintain ovarian follicular reserve. Cell Death Dis. 10:560. doi: 10.1038/s41419-0191799-3

Conflict of Interest: DW declares interest in intellectual property described in U.S. Patent 8,642,329, U.S. Patent 8,647,869, U.S. Patent 9,150,830, and U.S. Patent $10,525,086$.

The remaining author declares that the research was conducted in the absence of any commercial or financial relationships that could be construed as a potential conflict of interest.

Publisher's Note: All claims expressed in this article are solely those of the authors and do not necessarily represent those of their affiliated organizations, or those of the publisher, the editors and the reviewers. Any product that may be evaluated in this article, or claim that may be made by its manufacturer, is not guaranteed or endorsed by the publisher.

Copyright (c) 2022 Alberico and Woods. This is an open-access article distributed under the terms of the Creative Commons Attribution License (CC BY). The use, distribution or reproduction in other forums is permitted, provided the original author(s) and the copyright owner(s) are credited and that the original publication in this journal is cited, in accordance with accepted academic practice. No use, distribution or reproduction is permitted which does not comply with these terms. 